\title{
Los cofrades de las hermandades de Jesús el nazareno en el reino de Murcia a mediados del siglo XVII
}

The brothers of the brotherhoods of Jesus the Nazarene in the kingdom of Murcia in the mid-seventeenth century

\author{
Vicente Montojo Montojo1/Federico Maestre de San Juan Pelegrín2 \\ ${ }^{1}$ Real Academia Alfonso X el Sabio, Académico Numerario, España (vicente.montojo@um.es) \\ ${ }^{2}$ Real Academia Alfonso X el Sabio, Académico Correspondiente, España (histor51@hotmail.es)
}

Recibido el 15 de Junio de 2017; revisado el 09 de julio de 2017; aceptado el 18 de julio de 2017; publicado el 01 de septiembre de 2017

RESUMEN: La investigación sobre los componentes de las hermandades de Jesús Nazareno de Cartagena y Murcia ha permitido comprobar que hasta casi finales del XVII fueron artesanos y desde finales del mismo fueron comerciantes y mercaderes, además de artesanos, o ya en el XVIII se añadieron nobles. Tal evolución se manifestó en que, en una primera época, los logros artísticos de los artesanos fueron escasos, mientras que la incorporación de mercaderes y comerciantes originó que se ampliaran y ornamentaran capillas e incluso se incorporaran imágenes valiosas, pero los mayores logros se obtuvieron a mediados del XVIII, con la incorporación de retablos y esculturas o pasos de conjuntos de imágenes, entre los que destacaron los del escultor Francisco Salzillo.

PALABRAS CLAVE: Historia Moderna, Historia del Arte, Historia Social, Hermandades devocionales, Hermandades penitenciales, Historia de España.

\begin{abstract}
Research on the components of the brotherhoods of Jesus Nazarene in Cartagena and Murcia has shown that until the end of the seventeenth century they were craftsmen and since the end of the same were traders and merchants, as well as craftsmen, or as early as the eighteenth century noblemen were added. This evolution was manifested in the fact that in an early period the artistic achievements of the artisans were scarce, while the incorporation of merchants and merchants led to the enlargement and decoration of chapels and even the incorporation of valuable images, but the greatest achievements were obtained in the middle of the XVIII, with the incorporation of retablos and sculptures or steps of sets of images, among which the sculptor Francisco Salzillo..
\end{abstract}

KEYWORDS: Modern History, Art History, Social History, Devotionals Confraternities, Penitentials 
Brotherhoods, Spain History. 


\section{Introducción}

Los inicios de la Cofradía de Nuestro Padre Jesús Nazareno (Marrajos), de Cartagena, han sido hasta 2017 un reto para la investigación, puesto que apenas se sabía nada de ellos hasta 1995, y algo parecido se puede decir de la Cofradía de Jesús, de Murcia, hasta 1999. Nuevas investigaciones sobre las personas que figuran en la documentación notarial generada por la adquisición de las capillas de ambas cofradías nos aportan aspectos totalmente desconocidos de su historia en los años 1641-1648 y décadas siguientes, pero dan luz, por el método archivístico, sobre los orígenes de otras.

La primera etapa de la existencia de la primera cofradía que nos es conocida, es decir, la década de los años cuarenta del siglo XVII, fue una época marcada por la adquisición de la capilla en 1641 y por su pago entre 1642 y 1645, que se caracterizó por la intervención de personas de diversas profesiones, no de una exclusiva (la Hermandad de la Pesquera, como tradicionalmente se había mantenido hasta entonces) y por otra parte coincidió con la participación de otras hermandades en procesiones también pasionarias.

Cuando, en 1641, los mayordomos de la Cofradía de Jesús Nazareno adquirieron a los dominicos del Convento de San Isidoro de Cartagena una capilla situada en un lateral de la iglesia, podemos decir sin temor a equivocarnos que el cenobio experimentó entonces un buen momento constructivo, pues por una parte fue objeto de obras de ampliación para las que adquirió madera, así del dormitorio y sacristía, y por otra obtuvo donaciones de particulares y ayuda del Ayuntamiento de Cartagena, tanto en donativos para las obras, como por un convenio para poner estudio de gramática en el convento, pero al servicio también de seglares.

Algo parecido se puede decir de la Cofradía de Jesús de Murcia. Fue promovida por los frailes agustinos del Convento de la Virgen de la Arrixaca (1600), de la que recibió una imagen de un Jesús Nazareno que se trajo de Roma. En los años 1621-1640 adquirió diversas imágenes de cartón que se procesionaron, gracias a la gestión de sus mayordomos, que fueron casi todos artesanos, algunos relacionados con la seda, pero se perdieron todas, salvo la del titular, en la riada de San Calixto (1651). Tras este desastre, los mayordomos Damián Ferrer y Pedro Castaño consiguieron que se hicieran otras imágenes, que fueron de escaso valor, comparadas con las de los Salzillos. La reconstrucción de las biografías de estos comitentes artesanos o mercaderes y de los artistas a los que recurrieron, en aplicación del método prosopográfico, tiene de valor que se realiza 
sobre grupos sociales poco conocidos, como fueron los de quienes fueron mayordomos y cofrades procedentes del artesanado, el comercio o los labradores.

Así, entre 1619 y 1638, el convento dominico de Cartagena estipuló con los comerciantes genoveses Octavio y Jácome Corvari la ampliación de la capilla colateral al evangelio para sus sepulturas, que habían comprado a María Ayllón y Bolea, viuda del francés Julián Junge (1616), por razón de las obras del convento (Archivo Histórico Provincial de Murcia -AHPM-, Notariado -Not.5.434, 23 y 29.8.1619, fs. 532-533 y 539-542; les costó 400 reales). El convento compró madera en diversas partes, como Moratalla, en cuyas sierras abundaba, a Pedro Pierres, un maderero francés (1623) (5.414/235-6, 5.7.1623: este modo de citar indica $n^{\circ}$ de protocolo/folios), o Huéscar (Granada), a alguien cuyo nombre desconocemos. El prior y los religiosos obtuvieron licencia y donativos del ayuntamiento para ampliar el convento varias veces (Archivo Municipal de Cartagena -AMC-, Ac.Cap. 1637-1639/696-7, 7.5.1639). Estos inicios fueron paralelos en Málaga a los de la Hermandad del Cristo del Calvario, la Hermandad de Viñeros y la del Cristo de la Humildad y paciencia (Reder, 1994).

Ahora bien, los dominicos de Cartagena atrajeron el favor del ayuntamiento y convinieron el establecimiento de un estudio de gramática en el propio convento: enseñar en él a los hijos de los vecinos de esta ciudad, a todos los que quisieran ir a dicho estudio, por tiempo de un año, que había de correr y contarse desde 12 de julio de 1640, en la forma que se acostumbraba y otras veces se había hecho, por cuyo trabajo y ocupación le había de pagar esta ciudad a dicho convento 2.000 reales por tercias partes, de 4 en 4 meses, que la primera sería a 12.11.1640 (5.402/298-9, 1640).

Las cofradías devocionales y penitenciales dieron entonces continuidad a la obra de misericordia de Tobit, según el Libro de Tobías del Antiguo Testamento: la de enterrar a los muertos y contribuir con su presencia a las oraciones por ellos en sus funerales.

La Cofradía del Rosario del convento dominico de Cartagena experimentó entonces una buena época, pues Fernando de Arce y Gamboa, regidor del Ayuntamiento, recibió del convento una sepultura para Ana de Arce y Gamboa, su hija, en la Capilla de la Cofradía del Rosario, hasta tanto que encontrara otro sitio una vez acabadas las obras del convento (1619) (5.434/544-5, 31.8.1619), y en los años 1630-1638 recibió donaciones, como la de un retablo que encargó Juana Digueri, señora de Cúllar (Granada), viuda del comerciante genovés Deodato Imperial. Coincide precisamente este periodo de gran actividad constructiva y de recepción de donaciones (el retablo mencionado) y de 
limosnas (la de Juana Martínez de Escobar, en 1631), con su protagonismo en las procesiones penitenciales.

Aún en 1642, al año siguiente del contrato con la Cofradía de Nuestro Padre Jesús Nazareno, el Convento de San Isidoro vendió al licenciado Francisco Velázquez, presbítero y comisario del Santo Oficio de la Inquisición, la sacristía del convento, que ya estaba hecha, a la parte del evangelio, para que fuera suya y de sus herederos, con facultad para enterrar y todo lo demás que con decencia se pudieran servir de la sacristía, adornarla a su voluntad y de sus herederos, y poner sus escudos de armas, entierros y dotación (5.382/318-21, 20.9.1642).

\section{Hermanos mayores y mayordomos de la Cofradía de Nuestro Padre Jesús Nazareno en la década 1641-1650}

\subsection{Antonio Pardo}

Sólo de Antonio Pardo consta que fue hermano mayor de la Cofradía, en 1641, sin que sepamos de ningún otro. Estaba casado con Ana Martínez, quien hizo testamento el 9 de diciembre de 16411. En el testamento no hizo referencia alguna a la Hermandad de Jesús Nazareno, ya fuera porque la cofradía estuviera apenas implantada, ya por cualquier otro motivo. Sí nos ofrece algunos datos interesantes relativos al entorno familiar de Antonio Pardo. Por ejemplo, Ana Martínez era cuñada de Damián de Iniesta, un jurado del Ayuntamiento de Cartagena, hermano de un mercader, asesinado en 1630 y dejó viuda a Isabel Martínez de Escobar, hermana de Ana Martínez.

En cuanto a sus herederos directos Ana Martínez nombró a sus hijos: el presbítero licenciado Alonso Pardo y María Pardo, casada con Francisco Cerdán, pero dispuso que su marido Antonio Pardo retuviera la quinta parte de sus bienes para que los usufructuara mientras viviera, siendo heredados por sus hijos a su muerte (5262/261-2, 9.12.1641). Es posible, aunque no lo hayamos podido confirmar documentalmente, que Francisco Cerdán y María Pardo fueran padres de Juan Cerdán y Pardo, hermano mayor de la Cofradía de Jesús Nazareno en 1692 (Montojo, 1991, p. 92).

En cuanto a su profesión, Antonio Pardo era maestro mayor de la maestranza del rey, según obligación que siguió a la de venta de la capilla. El final de su vida culminó con un cargo militar,

${ }^{1}$ Ana Martínez, además, dejó en herencia a María Cerdán, su nieta, un censo o renta de 150 ducados de principal para ayudarla a tomar estado, es decir, para un buen casamiento. 
pero antes Antonio Pardo fue maestro carpintero, artillero y maestro artillero, según otros documentos notariales (Montojo, 1994, p. 553).

Su actividad como maestro carpintero se constató en 1640: Apoderó a Antonio del Castillo, carretero de bueyes y vecino de la Puebla de don Fadrique (Granada), para llevarle 26 cargos de madera ripia y colaña, por mitad, a 77 reales por cargo, adelantándole 1.300 reales y obligación de estar en Cartagena antes del 20 de noviembre (5332, 14.10.1640), y junto con Andrés Barcelón, vecino de Cartagena, a Pedro Fernández, carretero de bueyes y vecino de la Puebla de don Fadrique, para comprar en el Pinar del Duque de Alba, o donde los encontrara, 20 cargos de madera, los 8 de cuartones de a 20 palmos cada uno, otros 8 de ripia y colaña, y los 4 restantes de ripia apurados, a la persona y al precio que encontrase, llevarlos a Cartagena a lo largo de diciembre, para lo que adelantaron 1.300 reales y le pagarían 7 ducados por cada cargo $(5332,7.11 .1640)$.

La actividad profesional de Antonio Pardo no se limitó al ejercicio de esta actividad artesanal, sino que se extendió en esta misma época al servicio del rey. Además de ejercer como maestro carpintero, trabajó en 1630-1645 como artillero y cabo de artilleros, al servicio de la artillería real en la ciudad.

En 1632 fue encausado por don Juan de Escarramad, capitán de la artillería real, imputado de la muerte del jurado Damián de Iniesta (5324/382-4, 24.12.1632). El proceso judicial prosiguió en 1634, pues su hijo Alonso Pardo, clérigo de corona, dio poder a don Cristóbal Melgarejo, arcediano de Zamora y camarero del rey, para pedir al papa que le dispensase de la irregularidad en que había incurrido por el asesinato de Damián de Iniesta, que se le imputaba a Antonio Pardo (5299/142, 3.2.1634).

En 1639 como cabo de artilleros apoderó a Juan de Balbuena, presbítero de Madrid, para cobrar al pagador de la artillería de España lo que se le debía de su sueldo de cabo de artilleros y 1.480 reales de vellón que adeudó otra persona por cobrarlos por él al mencionado pagador, en razón de dos nóminas, una de 13 de febrero de 1636 y otra de 8 de febrero de 1637 (5303, 30.10.1639).

Las fechas de estas nóminas nos indican que estuvo varios años trabajando al servicio de la artillería real. En 1639 figuró con el cargo de maestro mayor de carpinteros, vinculado a la artillería real, pues por una carta de pago reconoció haber cobrado del pagador de armadas y fronteras 341 reales de vellón y 6 maravedíes por los salarios de 29 días que había dedicado en ir a Murcia y otras 
partes para embargar los carros necesarios para llevar a Madrid 300 quintales de pólvora (5303, 27.6.1639).

Como tal maestro mayor de carpinteros de la artillería real de Cartagena proporcionó madera para los cañones: en 1639 reconoció recibir 377 reales de vellón del pagador de armadas y fronteras por la cureña hecha para un cañón de la artillería de la ciudad, que se apeó, y por 3 pares de ruedas y ejes para otras piezas y otros reparos que había hecho en otras cureñas, como constaba de la libranza del teniente de la artillería de Cartagena, de fecha 20 de julio de 1638 (5303, 27.6.1639).

Finalmente, en relación con esta actividad artillera, puede también mencionarse que prestó 3 arrobas y media de pólvora, a 3 reales la libra, a don Ginés Rosique, regidor y capitán de la artillería del Concejo de Cartagena, para las salvas de artillería con que se celebró la fiesta de la Resurrección de Jesucristo de 1640, por lo que Antonio Pardo reclamó posteriormente que se le pagasen los 262 reales y medio que costaba la pólvora prestada y se comprometió a devolver los dos candeleros de plata empeñados don Ginés Rosique (AMC, Ac.Cap. 1640-1642/85, 5.5.1640).

Antonio Pardo murió en Badajoz en servicio del rey, por lo que su yerno Francisco Cerdán y su hija María Pardo apoderaron al licenciado Alonso Pardo, su otro hijo, para que cobrase todos los bienes de su herencia $(5263 / 3,12.1 .1641)$. Tales actividades de artillero, cabo de artilleros y maestro de carpinteros o de la maestranza del rey, se comprenden en su verdadero contexto si tenemos en cuenta que España llegó entre 1625 y 1643 al culmen de una escalada belicista a la que condujo la política, llamada de reputación, del conde duque de Olivares, valido de Felipe IV.

1634 fue el año de la batalla de Nordlingen (Alemania), en la que las tropas de la liga católica del Imperio Germánico, entonces bajo la dinastía Habsburgo, ayudadas por tropas de España, dirigidas por el cardenal infante don Fernando de Austria, hijo de Felipe IV, vencieron al ejército de Gustavo Adolfo de Suecia y la liga protestante alemana, que entonces predominaba. Pero esta victoria provocó que en 1635 Francia entrara en guerra con España, que luchaba desde 1621 contra Holanda, para evitar que se independizara (1621-1648) y temporalmente con Inglaterra (1625-1630), Suecia (1626-1635) y Francia (1628-1631) en la guerras del Báltico, La Valtelina y Monferrato (Kamen, 1991, p. 535). La victoria de Nordlingen fue un triunfo de España y la liga católica alemana, inesperado por Francia, que arrastró a esta potencia a intervenir en la Guerra de Alemania o de los Treinta Años (1618-1648) (Kamen, 1991, p. 536-9). 
Esta diversidad de conflictos exteriores y rebeliones ocurridas en distintos territorios de España (Cataluña y Portugal a partir de 1640, Nápoles en 1647) condujeron a las derrotas de sus armadas y ejércitos en Europa, como fueron fundamentalmente las batallas de las Dunas (1639), en la que los holandeses destrozaron gran parte de la armada española, y Rocroi (1643), uno de los primeros y grandes reveses de los tercios españoles de Flandes.

Se comprende que en dicho período la proveeduría de armadas y fronteras y la artillería real fueron instituciones muy activas en Cartagena. La fábrica de pólvora fue uno de los pocos organismos suministradores militares que la corona mantuvo bajo administración directa, sin concederla a asentistas genoveses o portugueses, como se hizo con el suministro de pólvora del distrito granadino, que en 1638 fue concedido al portugués Antonio Grafión o Grafior (Thompson, 1981, p. 308 y 270). Por otra parte, contó con un territorio muy rico en salitre (Abanilla, Alhama de Murcia, Caravaca de la Cruz, Totana) y salitrerías, como la fábrica del genovés Marco Jofredo en Cartagena (5283/51-2, 23.5.1642). Aún así la fábrica de Cartagena no fue capaz de dar abasto a todo su territorio jurisdiccional, posiblemente a causa de la gran demanda que producían los diferentes frentes de guerra. Por ello Juan Alférez Carrillo, teniente del capitán general de la artillería de España, contrató en 1637 con Juan Bautista, polvorista, vecino de Caravaca, el suministro mensual de una arroba de pólvora de munición (un quintal cada 4 meses) durante el tiempo que tuviera el mortero para fabricar pólvora a mano en Caravaca, por precio de 2 reales por libra, de acuerdo con una cédula real que tenía el marqués de Castrofuerte para hacer asientos con los polvoristas (705/79, 28.3.1637).

En definitiva, Antonio Pardo pudo prosperar desde maestro carpintero a oficial del rey y se convirtió en una persona importante en la ciudad. Ello explica o realza su nombramiento de hermano mayor. Aunque es posible que dicho nombramiento tuviera que ver con su relación con los dominicos del Convento de San Isidoro, pues en los años anteriores el convento realizó diversas obras de construcción o reparación y Antonio Pardo proporcionó madera. De hecho se documenta en estos años el transporte de madera de Huéscar, población que era señorío del duque de Alba, al igual que la Puebla de don Fadrique (Garzón, 1977, p. 601), para el Convento de San Isidoro de Cartagena. La capellanía conseguida a su hijo le facultó para celebrar misa en la iglesia conventual.

Su hijo, el licenciado Alonso Pardo mejoró también su carrera eclesiástica. En 1638 fue admitido en la Cofradía clerical de San Fulgencio, siendo clérigo de menores órdenes, con condición de que residiera en Cartagena 2 años, llegó a ser mayordomo de la cofradía en 1647, siendo 
presbítero (Colección Privada Cañabate -CPC-, San Fulgencio/72 y 88, 1.2.1638 y 1.2.1647). A partir de 1639 tuvo primero una capellanía y luego un beneficio eclesiástico. En 1639 Antonio Pardo, su padre, le obtuvo la capellanía mencionada que había fundado doña Juana Martínez de Escobar, viuda del licenciado Ginés García, abogado, de la que fue nombrado patrón junto con doña María Martínez de Escobar, y quedó vacante por el fallecimiento Francisco Méndez Muro (5303, 15.6.1639). Alonso Pardo ocupó esta capellanía, de tal forma que en 1642, tras la muerte de su padre, apoderó a Francisco Cerdán, su cuñado, al licenciado Francisco Ibáñez, presbítero, y a Francisco López, procurador del número de Cartagena, para cobrar todo el dinero que le fuera debido en razón de la capellanía, así como por otras que tuvo a su cargo, por obligaciones, cédulas y partidas de cuentas, y a Juan de Cuenca Murillo lo que le debía del arrendamiento de la vara del palio del Santísimo Sacramento (5262/502-3, 19.12.1642).

\subsection{Ginés Martínez Fortún}

Ginés Martínez Fortún, yerno de Miguel Abril, fue mayordomo en 1641 y maestro alpargatero según apoderó a Luís Navarro, vecino de Orce (Granada), para cobrar a Ginés Franco, de Orce, 400 reales que le prestó y tuvo que devolverle en cáñamo (5383/58, 19.4.1643). Ginés tuvo una pequeña finca rústica. Juan Sánchez Vega, yerno de Diego Martínez Fortún, se obligó a pagarle 1.700, por 8 tahullas de viña despoblada, 6 fanegas de tierra blanca, una casa, un pozo y un ejido en el pago o paraje de Moncada, que Ginés había heredado de su hermano Diego, religioso franciscano (5384/124-5, 21.5.1645).

En 1645 Ginés Martínez Fortún testó: dispuso ser enterrado en la Capilla de Jesús Nazareno, con túnica y cordón de la cofradía. Tuvo cuenta con Juan Lorenzo Rato, que le proporcionó cáñamo a cambio del hilo que él dio para las almadrabas de Cabo de Palos y Escombreras, de la que resultó deberle Rato 6.635 reales.

Dejó sus bienes en herencia a sus hijos Juana Bolea (así se llamaba la madre de Ginés Martínez Fortún), a la que decidió mejorar con 1500 reales, a Diego, Miguel y Bernardo Martínez (5284/155-7, 24.12.1645). 


\subsection{Simón García Campero}

Simón García, mayordomo en 1642 y 1645, de quién se dijo que fue Simón García Angosto (Montojo, 1991, p. 92), fue Campero de segundo apellido y: pescador. Propietario de una barca y de una jábega cuando casó con Catalina Mínguez, hija de Ginés Mínguez y Catalina Martínez, según escritura de dote e inventario de sus bienes (6169/493-5 y 496, 22.11.1637).

En su testamento $(5386 / 166-7,1648)$ dispuso su entierro en la capilla de la cofradía con túnica de color morado. Tuvo compañía con Juan Gallardo el mozo para compraventa de barrilla y fue hermano de Agustín García Campero, personaje importante después de la epidemia de 1648 (Hernández/Montojo, 1993).

\subsection{Pedro Botija}

Otro mayordomo de 1645, Pedro Botija el mayor, fue maestro albañil o alarife, una profesión de gran importancia unas décadas antes en Cartagena, probablemente por causa del crecimiento demográfico y económico de la ciudad hasta 1620. El crecimiento numérico de maestros y oficiales albañiles dio lugar a la constitución de la cofradía gremial del Ángel Custodio (Montojo, 2000, p. 258), que edificó una ermita junto a las Laguenetas, en el Camino de San Juan. Entre sus primeros componentes estuvo Jerónimo García Botija, yerno de Zabala (5162/364-6, 4.7.1599).

No fue hasta 1647 cuando se formalizó la liquidación de una parte de esta herencia: José Díaz, maestro de albañilería, casado con Ana Rubio, reconoció entonces recibir de Pedro Botija el mayor y Ana Muñoz, su madre, lo que le correspondió de la herencia de Miguel Díaz, su padre, además de otros "por cuenta de la legítima de la dicha Ana Muñoz, su madre": entre ellos dos túnicas, una morada y otra negra, es decir, de las hermandades de Jesús Nazareno y de Cristo Crucificado, respectivamente $(5386,21.7 .1647)$.

Pedro Botija el mayor y Martín Ponce, ambos maestros alarifes, fueron veedores del oficio de albañiles en 1634: se obligaron junto con otros albañiles (Pedro Sivilla, Luís de Sivilla, Mario Martínez, Juan García Serrano, Antón Ros, Juan Díaz, Diego Manzanares, Alonso Franco, Juan Martínez y Francisco Basol), en nombre de todos los demás a recoger dinero (4 cuartos cada primer sábado de mes) y a destinarlo a encargar un pendón del oficio para que saliera en las procesiones $(5299 / 226,24.6 .1634)$. 
La actividad profesional de Pedro Botija el mayor como maestro de albañilería debió ser muy variada. Fabricó tapias de piedra y lodo en casas de campo, como 50 para Juan Martínez Cantos, en una casa de su heredad situada en el pago de Los Majuelos, a finales de 1641, por 250 reales, en el plazo de seis meses $(5381,31.12 .1641)$, un encargo que años después fue anulado, a causa de la insolvencia económica del contratante (5384, 28.8.1644).

Hizo otras obras tanto de construcción como de reparación, aunque fueron generalmente modestas, a diferencia de Jerónimo Botija, su padre, que las hizo en el muelle de San Leandro, que proyectó y dirigió, como también su puerta (Hernández/Segado, 1980, p. 314), y en el nuevo Ayuntamiento (1622) (Tornel, 2001, p. 139), pues se obligó a favor de Francisco Ortega a derribar y volver a fabricar una pared de 25 palmos en una casa del segundo y a echar un pie en la frontera de la calle de dicha casa y un aspa en la frontera, todo de cal y canto, por su cuenta y riesgo y precio de 300 reales $(5384,2.4 .1645)$.

Realizó pequeños negocios, que pueden mostrar una situación económica holgada entre 1641 y 1644: compró un rocín, mediano de cuerpo y de pelo castaño, a Nicolás de Alba, vecino de Granada, por 300 reales $(5381,8.3 .1641)$, y una casa descubierta en el Carrerón de los Ortuños, fuera de la Puerta de Murcia, a Juan Martínez Escobar, yerno de Gregorio Martínez, y Juan Martínez, yerno de Bartolomé de Siles, por 700 reales de vellón (5283/99-100, 3.11.1641).

Quizá su situación fuera más estrecha en 1647, pues vendió un carro herrado y una mula por 1550 reales $(5386,20.9 .1647)$. No sabía escribir. Sobrevivió a la epidemia de peste de 1648: reconoció recibir 105 ducados de Pedro Pérez de Tudela por una deuda (5233/22, 9.7.1649).

No fue Pedro Botija, desde luego, un maestro alarife de prestigio regional, como lo fue Pedro Milanés, maestro cantero vecino de Murcia, quien en 1645 recibió del capitán Juan Carlos Tacón, genovés, el encargo de labrar una portada de mármol blanco para su casa de la Calle Mayor de Cartagena, de 18 palmos de alto y 10 de ancho, con el mármol que el genovés le entregaría, pagándole éste 500 reales, 100 por adelantado y 400 acabada la obra, para lo que se dio plazo de 50 días (5384/240-1, 7.10.1645). Esta portada recuerda a la realizada por otros dos canteros de Murcia, para Diego Báez Coronel, jurado y vecino de Murcia, hermano de Pedro Báez, jurado y vecino de Cartagena, de estilo parecido aunque más recargado. El valor en dinero de los contratos que conocemos suscritos por Pedro Botija el mayor era de aproximadamente la mitad de la cantidad que estipuló Pedro Milanés en 1645. 
Puede decirse de ellos que negociaban, compraban y vendían, como se dice de otros muchos en los evangelios.

\section{Cofrades y mandas piadosas de los años 1641-1648}

Diversas personas manifestaron en esos años su pertenencia a la cofradía: Pedro Pascual dispuso en su testamento, por poder a Francisco Valero, que se le enterrara en la capilla de la Cofradía de Jesús Nazareno, de la que era hermano, con la túnica morada, y que se diesen 10 ducados de limosna a la cofradía $(5233,15.3 .1644)$.

Otra cofrade, Juana de Robles, dispuso que fuera sepultada en la capilla de la cofradía, en razón de la pertenencia a ella de su marido, Jerónimo Hernández, y fundó además (1645) una pía memoria de una misa rezada anualmente en dicha capilla, el día de San Juan de Junio, dejando como dotación una limosna de 2 reales anuales, cargada dicha renta sobre una casa que tenía en la Puerta de Murcia (5284/31-3, 20.3.1645).

Otra mujer, Catalina García, mujer de Bartolomé Tobar, maestro albañil, dispuso su sepultura en la capilla de la cofradía: "Mando que cuando Dios nuestro Señor sea servido de me llevar de esta presente vida mi cuerpo sea sepultado en el Convento de Señor San Isidoro de esta ciudad, en el carnero de la Hermandad de Jesús de Nazareno, de que soy hermana" (5307/81-2, 9.5.1646). Juan de Osuna hizo una declaración y una disposición testamentarias semejantes: que era cofrade y que fuera enterrado con la túnica morada $(5386,28.6 .1647)$.

\section{La participación de otras cofradías en las procesiones de Semana Santa}

De lo referente a Pedro Botija se deduce que participaron en las procesiones pasionarias otras hermandades, como las de la Oración en el Huerto, del Cristo de la Columna y de Cristo Crucificado.

De la Hermandad de la Oración en el huerto sus comisarios Juan García Motarre, maestredaja, y Hernando Martínez, albañil, se obligaron a pagar a Martín Callen Pérez, cerero, lo que costase la cera blanca que fuese consumida por las 40 hachas que les había entregado, a 9 reales la libra, más lo que costase el alquiler de las 40 hachas a 6 reales cada una, para lo que adelantaron 400 reales y se comprometieron a pagar en 2 meses (5262/309-10, 15.4.1642).

De la segunda, la de Cristo en la Columna, el 18 de marzo de 1640 el mismo Martín Callen Pérez, maestro cerero, se obligó a entregar 40 hachas de cera blanca a Miguel Julián, carpintero, y a 
Juan García Botoloscardos, vecinos de Cartagena, comisarios de aquella, para el Viernes Santo siguiente, con el fin de que sirvieran para alumbrar la imagen en la procesión que se haría el Viernes Santo por la noche por las calles de la ciudad, pagándole de alquiler a 8 reales cada libra de cera, a 6 reales de alquiler por hacha de las enteras que les fueren entregadas y a 4 reales las empezadas, para lo que los comisarios le adelantaron 200 reales (5282/56, 18.3.1640).

Dos años después Pedro Botija, albañil, yerno de Diego de Gracia, se obligó a pagar a Martín Callen Pérez, cerero, lo que costase la cera necesaria para 20 hachas de cera blanca que le había entregado para la Hermandad del Santo Cristo de la Columna, para la procesión del Jueves Santo, de la que era comisario aquél, a 9 reales la libra, más el alquiler que costasen las 20 hachas, de 6 libras de cera cada una, a 6 reales el hacha, para lo que le adelantó 200 reales y se estableció plazo de 2 meses para pagar lo que se adeudase (5262/308-9, 15.4.1642).

La Hermandad del Santo Cristo Crucificado salía el Viernes Santo. Juan Bautista Alfonso y Pedro Antonio Pereti, el último genovés, declararon haber pleiteado ante la justicia de Cartagena por gastos hechos como comisarios de la hermandad en la procesión del Viernes Santo de 1646. Juan Bautista Alfonso reclamó a Pedro Antonio Pereti 1.200 reales. Llegaron a un acuerdo mediando otras personas: Pereti se obligó a pagar 600 reales a Alfonso, para el 1 de agosto, por deuda de cuenta de túnicas de bocasíes negros que Pereti puso para la procesión y hermandad (5386, 28.6.1647). Juan Bautista Alfonso cedió a Agustín Lamberto el menor la deuda de Pereti y le apoderó para que le cobrara 600 reales que no había pagado en la fecha establecida $(5386,9.8 .1647)$.

\section{Conclusiones}

Al iniciarse la década de 1640, concretamente en 1641, la Hermandad de Jesús Nazareno adquirió una capilla en el Convento de San Isidoro de Cartagena, de los frailes dominicos. Se realizaron obras en el convento dominico, de forma que en 1635 fray Diego Eugenio, procurador del convento, solicitó y obtuvo del Concejo de Cartagena una ayuda de 200 reales para la obra hecha y en 1637 obtuvo 500 reales para dos aljibes. En la iglesia del convento la Capilla del Rosario estaba en obras. Por ello fue objeto de diversas limosnas para su construcción, como la de 500 ducados que hizo el rico mercader genovés Juan Bautista Prebe (5299/392-5, 10.12.1634). El 31.4.1641 el convento hizo una nueva ampliación al comprar la casa de Magdalena López a Ginés Rosique, regidor del concejo, curador o tutor de Magdalena, por 1.200 reales más un censo o renta anual de 60 reales. Unos meses después fray Diego Eugenio vendió una capilla a la Hermandad de Jesús Nazareno por 1.400 reales, 
dinero que posiblemente englobó el valor de la casa adquirida y de lo correspondiente a la renta durante unos años.

La Cofradía de Jesús de Murcia recibió la donación de la Capilla de las Once mil Vírgenes en la Ermita de la Virgen de la Arrixaca (1626), que tenían los agustinos calzados, pero como en Cartagena la capilla fue pequeña y las 2 cofradías las ampliaron: la de Cartagena en 1695-1731 y la de Murcia en 1670-1676. Ello no fue obstáculo para que las dos consiguieran obras de arte, tanto la Capilla Marraja en sí (su interior sobre todo y su retablo barroco, de Nicolás de Rueda), como la Iglesia de Jesús en Murcia por su monumental portada.

¿Quiénes fueron el hermano mayor y los mayordomos de las cofradías que compraron la capilla o edificaron la iglesia? En Cartagena el maestro carpintero Antonio Pardo y los maestros albañiles Pedro Botija y Martín Ponce, idóneos para adquirir la capilla y prestar ayuda a los dominicos. Sin caer en simplificaciones: participaron, además, Ginés Martínez Fortún, maestro alpargatero, y Simón García Campero, arráez de la Pesquera.

Pero varias hermandades realizaron las procesiones del Jueves y del Viernes Santo, con imágenes que representaron diversas escenas de la Pasión y Muerte de Jesucristo. Todo esto antes de 1648, cuando la gran epidemia de peste provocó el declive de estas hermandades hasta 1661-1663, pues desaparecieron todos sus miembros. Posteriormente fueron restauradas las hermandades de Jesús en la Columna y de Jesús Nazareno. Sus miembros formaron un colectivo de personas con profesiones modestas, artesanos representados por dos albañiles, un curtidor, dos herradores, un herrero, un espartero, un cerero y un alpargatero, o 4 labradores, 3 pescadores, 3 taberneros, un tendero y un escribano.

Tras pocos años de existencia se produjo la gran mortandad de la epidemia de peste bubónica. Se otorgaron 8 testamentos en 1648, que sumados a otros 9 desde 1641 y a la defunción en 1642 de Antonio Pardo, primer hermano mayor, y al testamento de Bartolomé Tovar, que en 1660 dijo que fue uno de los hermanos fundadores de la cofradía, da un total de 19 testamentos. El número de personas que formaron el primer núcleo de la hermandad pudo estar entre 30 y 40, máxime cuando de todas las personas nombradas 14 fueron hombres, y a los que se sumaron otros hermanos que tampoco testaron. 
Fue rotunda la voluntad de casi todos los cofrades de ser enterrados con las túnicas moradas que utilizaron en procesiones y de se solicitar el lugar de su enterramiento en las bóvedas subterráneas bajo el suelo de la capilla. De 42 testamentos de hermanos 40 pidieron ser enterrados en la capilla, el primero Pedro Pascual, labrador (5.334/140-1, 1642).

Tal evolución la experimentó también la Cofradía de Jesús de Murcia y si la de Cartagena llegó a conseguir una gran capilla y un gran retablo, la de Murcia consiguió una iglesia y un gran conjunto de esculturas o pasos de imágenes realizados por Francisco Salzillo Alcaraz, tras un cambio social, pues de los artesanos y mercaderes de finales del XVII se pasó a un grupo de nobles como promotores de los encargos a Salzillo. Se comprueba así la eficacia de una investigación sobre los protagonistas de los encargos y sobre un estudio micro-histórico de sus biografías.

\section{Referencias bibliográficas}

GARZÓN PAREJA, Manuel (1977), "Señoríos del Reino de Granada", en Boletín de la Real Academia de la Historia, 174, pp. 597-602.

HERNÁNDEZ ALBALADEJO, Elías, SEGADO BRAVO, Pedro (1980), “Arquitectura y Contrarreforma", en Historia de la Región Murciana, Murcia, t. 6.

HERNÁNDEZ FRANCO, Juan, MONTOJO MONTOJO, Vicente (1993), “Cultura del honor, linajepatrón y movilidad social en Cartagena durante los siglos XVI y XVII”, en Hispania, 185, pp. 1009-1030.

KAMEN, Henry (1991), "La política exterior", en Historia General de España y América, t. 8, Madrid, pp. 521-560.

MACIÁ CAÑABATE, F (1989). “Una aclaración sobre el origen del apelativo "Marrajos”, en Ecos del Nazareno, p. 5.

MAESTRE DE SAN JUAN PELEGRIN, Federico (1999), "Semblanza histórica de los Hermanos Mayores de la Cofradía de Nuestro Padre Jesús Nazareno durante el siglo XVIII”, en Ecos del Nazareno 1999, Cartagena, p. 6.

MONTOJO MONTOJO, Vicente (1994) "De las Atarazanas al Arsenal", en MAS GARCÍA, J. (dir.) Historia de Cartagena, Murcia, 1986, t. 7, pp. 545-558. 
MONTOJO MONTOJO, Vicente (1991) "Los siglos XVI y XVII: Organización social y actividades religiosas, festivas y asistenciales”, en FERRÁNDIZ ARAÚJO, C./GARCÍA BRAVO, A. (coord.) Las cofradías pasionarias de Cartagena, Cartagena, pp. 33-130.

MONTOJO MONTOJO, Vicente (2000). “La diferenciación social”, en MAS GARCÍA, J. (dir.) Historia de Cartagena, Murcia, t. 8, pp. 243-274.

MONTOJO MONTOJO, Vicente y MAESTRE DE SAN JUAN PELEGRÍN, Federico (2003), “Los cofrades de la Hermandad de Nuestro Padre Jesús Nazareno a mediados del siglo XVII", Ecos del Nazareno 2003, Cartagena, p. 5.

REDER GADOW, Marion (1994), "Fray Alonso de Santo Tomás y la Cofradía de Ánimas de los Mártires”, Baética: Estudios de arte, geografía e historia, n. 16, pp. 357-382.

TORNEL COBACHO, Cayetano (2001). El Gobierno de Cartagena en el Antiguo Régimen (12431812), Murcia,

THOMPSON, Irving A.A. (1981). Guerra y decadencia: Gobierno y administración en la España de los Austrias, 1560-1620, Barcelona.

THOMPSON, Irving A.A. (1990), "Aspectos de la organización naval y militar durante el Ministerio de Olivares", en ELLIOT, J./GARCIA SANZ, A. (coordinadores), La España del Conde Duque de Olivares, Madrid, Crítica, pp. 249-274. 